\title{
Variant $\mathrm{LTC}_{4}$ synthase allele modifies cysteinyl leukotriene synthesis in eosinophils and predicts clinical response to zafirlukast
}

\author{
A P Sampson, S Siddiqui, D Buchanan, P H Howarth, S T Holgate, J W Holloway, \\ I Sayers
}

\section{Division of \\ Respiratory Cell and \\ Molecular Biology \\ Research, University \\ of Southampton \\ School of Medicine, \\ Southampton, UK \\ A P Sampson \\ $S$ Siddiqui \\ D Buchanan \\ P H Howarth \\ S T Holgate}

Division of Human

J W Holloway

I Sayers

Correspondence to:

Dr Tony Sampson, Medical

Specialties (825), Level F,

South Block, Southampton

General Hospital,

UK

aps@soton.ac.uk
Genetics

Southampton SO16 6YD,

Clinical trials with leukotriene synthesis inhibitors and cysteinyl leukotriene (cys-LT) receptor antagonists have shown that cys-LTs $\left(\mathrm{LTC}_{4}, \mathrm{LTD}_{4}\right.$, and $\mathrm{LTE}_{4}$ ) are the predominant mediators of bronchoconstriction in response to diverse asthma triggers including allergen, PAF, sulphur dioxide, and non-steroidal antiinflammatory drugs (NSAIDs). ${ }^{1}$ In addition, inhalation of a single dose of a cys-LT causes persistent eosinophilia in the bronchial mucosa and sputum of asthmatic patients, ${ }^{23}$ and LT modifier drugs significantly reduce airway and blood eosinophilia in clinical asthma. ${ }^{4}$

We have shown that, in the asthmatic airway, eosinophils represent the majority of cells that express the terminal enzyme in the cys-LT pathway, $\mathrm{LTC}_{4}$ synthase, and hence have the capacity to generate cys-LT upon stimulation. ${ }^{5}{ }^{6}$ Inflammation and bronchoconstriction in the asthmatic airway may be sustained by a vicious cycle of cys-LT synthesis and eosinophil recruitment (fig 1). Anomalies in the genetic and cytokine factors that regulate cys-LT pathway enzymes in eosinophils may thus be central to the pathophysiology of asthma.

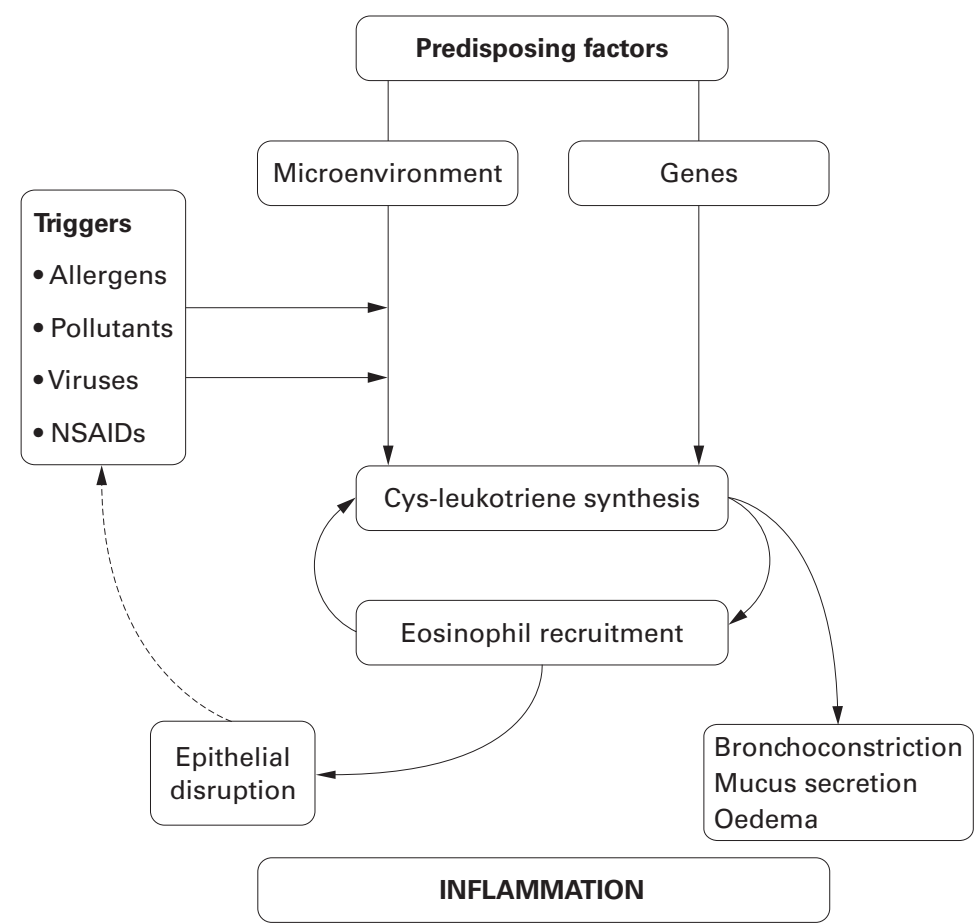

Figure 1 Schematic diagram illustrating that genetic and cytokine factors modulate the vicious cycle of cysteinyl leukotriene synthesis and eosinophil recruitment in the asthmatic airway.
Cys-LTs are synthesised from membrane derived arachidonic acid. During stimulusspecific cell activation, arachidonic acid released by phospholipases including cytosolic phospholipase $\mathrm{A}_{2}\left(\mathrm{PLA}_{2}\right)$ is translocated to the 5-lipoxygenase activating protein (FLAP) and converted in two steps to leukotriene (LT) $\mathrm{A}_{4}$ by 5-lipoxygenase (5- LO). $\mathrm{LTA}_{4}$ is converted to $\mathrm{LTB}_{4}$ by cells expressing $\mathrm{LTA}_{4}$ hydrolase, and/or to $\mathrm{LTC}_{4}$ by cells expressing $\mathrm{LTC}_{4}$ synthase, which conjugates $\mathrm{LTA}_{4}$ to reduced glutathione. After carrier mediated cellular export of $\mathrm{LTC}_{4}$, the sequential cleavage of glutamate and glycine residues provides the extracellular receptor active metabolites $\mathrm{LTD}_{4}$ and $\mathrm{LTE}_{4}$, respectively. Cys-LTs act at specific cys- $\mathrm{LT}_{1}$ receptors on target cells including bronchial smooth muscle and inflammatory leucocytes. ${ }^{78}$

The cys-LT pathway in eosinophils may be modulated by the cytokine microenvironment in the bone marrow, circulation, and airway. Maturation of eosinophils in vitro by the eosinophilopoietic cytokines interleukin (IL) -5 and IL-3 is accompanied by sequential expression of $\mathrm{PLA}_{2}$, 5-LO, FLAP, and $\mathrm{LTC}_{4}$ synthase, associated with acquisition of a cys-LT synthesising phenotype. ${ }^{9}$ In asthmatics, enhanced capacity of blood eosinophils to generate $\mathrm{LTC}_{4}$ may be caused by cytokine induction of 5-LO pathway enzyme expression, including FLAP. ${ }^{10}$ Induction of 5-LO pathway enzyme expression by the cytokine microenvironment may also be observable within the bronchial mucosa of mild asthmatics naturally exposed to a seasonal aeroallergen. ${ }^{6}$

The capacity for cys-LT synthesis of eosinophils may also be influenced by promoter polymorphism in the genes encoding cys-LT pathway enzymes. ${ }^{11}$ Promoter polymorphism in 5-LO is linked to modified gene transcription and a diminished clinical response to an LT synthesis inhibitor in a small proportion $(\sim 5 \%)$ of asthmatics, ${ }^{12-14}$ but this cannot account for the large subgroup of poor responders to LT modifier drug therapy.

In bronchial biopsy specimens of patients with aspirin intolerant asthma (AIA) who have a constitutively high baseline production of cys-LTs and generally good clinical responses to leukotriene modifier drugs, ${ }^{15}$ the numbers of cells expressing $\mathrm{LTC}_{4}$ synthase are four times more prevalent than in biopsy specimens from aspirin tolerant asthmatics (ATA) and 19 times more prevalent than in normal bronchial biopsy specimens. ${ }^{5}$ The increased prevalence of $\mathrm{LTC}_{4}$ synthase in biopsy specimens from patients with AIA is partly the result of an 
increased proportion of eosinophils expressing the enzyme $(50 \%$ versus $21 \%$ in patients with ATA) and correlates exclusively with raised cys-LT levels in bronchoalveolar lavage (BAL) fluid and with bronchial hyperresponsiveness to inhaled lysine-aspirin. ${ }^{5} \mathrm{~A}$ single nucleotide polymorphism in the $\mathrm{LTC}_{4}$ synthase gene promoter $\left(\mathrm{A}_{-44} \mathrm{C}\right)$ has been reported in $76 \%$ of patients with AIA compared with $42-44 \%$ in those with ATA and normal subjects. ${ }^{16}$ The variant (C) allele is associated with higher levels of $\mathrm{LTC}_{4}$ synthase mRNA in blood eosinophils, ${ }^{17}$ suggesting that the variant allele increases expression of $\mathrm{LTC}_{4}$ synthase and hence the capacity of these cells to synthesise cys-LT.

Since the variant $\mathrm{LTC}_{4}$ synthase genotype is found in a significant proportion of patients with ATA and normal subjects, ${ }^{16}$ we hypothesised, firstly, that eosinophils from subjects with the variant genotype may have a predisposition to enhanced synthesis of cys-LT when the 5-LO pathway is stimulated. Secondly, we hypothesised that the variant $\mathrm{LTC}_{4}$ synthase genotype may be more prevalent in severe persistent asthmatics, irrespective of aspirin sensitivity, than in normal subjects. Thirdly, we hypothesised that severe asthmatics with the variant genotype may represent a subgroup of patients in whom increased cys-LT synthesis is particularly important in impairing lung function, and hence that these patients may be synonymous with a phenotype of "responders" to anti-LT therapy.

\section{Methods}

Normal subjects $(\mathrm{n}=31)$ were adult volunteers with no history of chronic respiratory disease who were taking no medication. Four normal subjects were atopic as judged by skin prick tests. The 23 asthmatic patients $(6 \mathrm{M}, 17 \mathrm{~F}$; aged 25-76 years) had a clinical history of chronic, severe asthma uncontrolled by their existing medication. Three asthmatic patients reported a clinical history of aspirin sensitivity. All 23 asthmatic subjects were receiving inhaled corticosteroids, and 10 were also receiving oral steroids, 14 were receiving a long acting $\beta_{2}$ agonist, four were receiving theophylline, and one cyclosporin. At pre-study assessment, forced expiratory volume in one second $\left(\mathrm{FEV}_{1}\right)$ varied between 0.24 and 2.5 litres and peak expiratory flow (PEF) between 106 and $408 \mathrm{l} / \mathrm{min}$. During the study asthmatic subjects abstained from all medication except inhaled corticosteroids and inhaled $\beta_{2}$ agonists as required, and received oral zafirlukast $(20 \mathrm{mg}$ bd) for two weeks when lung function assessments were repeated. Although an open study of zafirlukast, patients and investigators were blinded to patient genotype.

Eosinophils were purified from the blood of normal subjects and their capacity for $\mathrm{LTC}_{4}$ synthesis assessed as previously described. ${ }^{10}$ Briefly, mononuclear cells and platelets were removed by Percoll discontinuous density gradient centrifugation, erythrocytes by hypotonic lysis, and neutrophils by negative immunomagnetic selection (MAC system) using anti-CD16 magnetic beads. Resulting eosi- nophils ( $>98 \%$ pure, $>96 \%$ viable) were cultured $\left(10^{5}\right.$ cells $\left./ 0.5 \mathrm{ml}\right)$ in HEPES buffered RPMI1640 medium at $37^{\circ} \mathrm{C}$ for 15 minutes in the presence and absence of calcium ionophore A23187 $(1 \mu \mathrm{M})$ and in the presence of the cyclo-oxygenase inhibitor indomethacin $(10 \mu \mathrm{M})$. Following extraction of intracellular LTs by methanol treatment, total cys-LT synthesis was quantified by Biotrak enzyme immunoassay (EIA; Amersham, UK). Urinary $\mathrm{LTE}_{4}$ levels were assessed as a marker of whole body cys-LT synthesis in normal subjects by EIA and corrected for creatinine.

Genomic DNA was isolated from whole blood using the QIAmp DNA Blood Mini Kit (Qiagen). The region flanking the $\mathrm{A}_{-44} \mathrm{C}$ polymorphism was amplified using PCR (forward primer 5' CTC CAT TCT GAA GCC AAA G 3' ; reverse primer: 5' AGA CCG CCT CAC CAC TT 3'). Alleles were genotyped using MspI restriction digestion of the 296 bp PCR product $^{16}$; an endogenous MspI site provided an internal control for the assay.

The study was approved by the Southampton \& SouthWest Hampshire Joint Research ethics committee and all subjects gave informed written consent to participate.

\section{Results}

The variant $\mathrm{LTC}_{4}$ synthase genotypes $(\mathrm{C} / \mathrm{C}$ and $\mathrm{C} / \mathrm{A}$ ) were observed in 13 out of 23 severe asthmatic patients (56\%) compared with only 10 of 31 normal subjects (32\%). The frequency of the variant allele (q) was thus 0.27 in the asthmatic patients and 0.19 in the normal subjects. Despite the small size of the subject
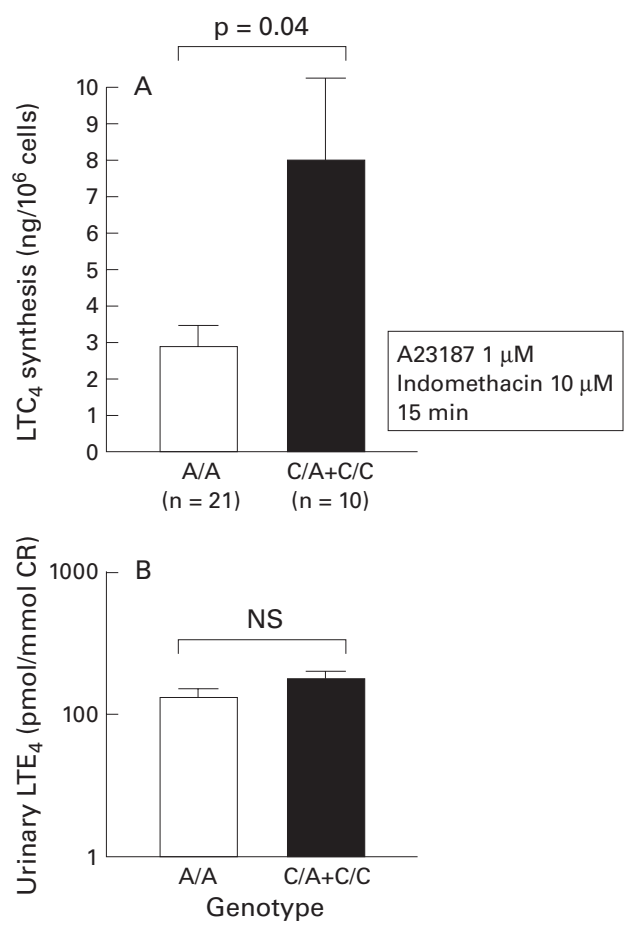

Figure 2 (A) Synthesis of $\mathrm{LTC}_{4}$ by calcium ionophore stimulated blood eosinophils from normal subjects with variant $(C / C$ and $C / A)$ and wild type $(A / A) L T C_{4}$ synthase genotypes. (B) Urinary $L T E_{4}$ levels in normal subjects with variant and wild type $L T C_{4}$ synthase genotypes. 


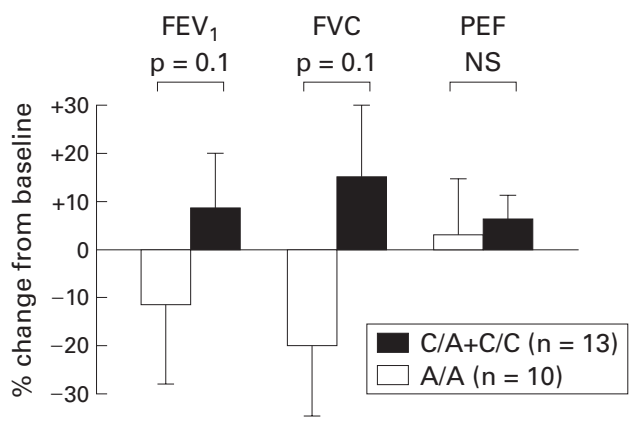

Figure 3 Percentage changes in lung function compared with pre-study values in severe asthmatics with variant $(C / C$ and $C / A)$ and wild type $(A / A) L T C_{4}$ synthase genotypes following oral therapy with the leukotriene receptor antagonist zafirlukast (Accolate; $20 \mathrm{mg}$ bd) for two weeks.

populations, the enhanced prevalence of the variant genotype in the asthmatic patients was statistically significant ( $p=0.04$, Fisher's exact test).

In normal subjects spontaneous production of LTC $_{4}$ from unstimulated blood eosinophils was not significantly different between the two genotype subgroups. However, when stimulated with calcium ionophore A23187 $(1 \mu \mathrm{M})$ in the presence of indomethacin $(10 \mu \mathrm{M})$ to block shunting of arachidonate substrate along the prostanoid pathway, blood eosinophils from patients with variant genotypes $(\mathrm{C} / \mathrm{C}$ and $\mathrm{C} / \mathrm{A}$ ) produced approximately three times more $\mathrm{LTC}_{4}\left(7.8(2.9) \mathrm{ng} / 10^{6}\right.$ cells, $\left.\mathrm{n}=13\right)$ than eosinophils from patients with the wild type genotype (A/A, $2.7(0.4) n g / 10^{6}$ cells, $\mathrm{n}=10 ; \mathrm{p}$ $=0.04$, Mann-Whitney test; fig $2 \mathrm{~A}$ ). There was no significant difference between normal subjects with the variant genotypes and those with the wild type genotype in urinary levels of $\mathrm{LTE}_{4}$ (145 (21) pmol/mmol versus 128 (8) $\mathrm{pmol} /$ mmol creatinine, respectively; $\mathrm{p}>0.2$; fig $2 \mathrm{~B}$ ).

In asthmatic subjects with variant $\mathrm{LTC}_{4}$ synthase genotypes, oral administration of zafirlukast (20 mg bd) for two weeks increased $\mathrm{FEV}_{1}$ by 9 (12)\% and forced vital capacity (FVC) by 15 (18)\% compared with pre-study values $(\mathrm{n}=13)$, with decreases of $-12(18) \%$ and $-18(15) \%$, respectively, in patients with the wild type genotype ( $\mathrm{n}=10$; both $\mathrm{p}=0.1$; fig 3 ). Home PEF values did not differ between the groups.

\section{Discussion}

The capacity of leucocytes to generate cys-LTs in response to allergic and non-allergic triggers may be modulated by the cytokine microenvironment in the asthmatic airway and by genetic factors (fig 1). The single nucleotide polymorphism $\left(\mathrm{A}_{-444} \mathrm{C}\right)$ described in the $\mathrm{LTC}_{4}$ synthase gene promoter has been postulated to enhance gene transcription and enhance cellular capacity for cys-LT synthesis. ${ }^{11}$ The variant LTC $_{4}$ synthase genotypes are reported to be highly prevalent $(76 \%)$ in patients with aspirin intolerant asthma ${ }^{16}$ who have constitutively increased cys-LT synthesis and good clinical responses to anti-leukotriene therapy, and are also common (42-44\%) in normal subjects and patients with aspirin tolerant asthma. The results presented here provide preliminary evi- dence that, irrespective of aspirin sensitivity, the variant genotypes confer an increased capacity for cys-LT synthesis in eosinophils, the predominant cell type expressing $\mathrm{LTC}_{4}$ synthase in the asthmatic airway, and that in severe asthmatic patients, the variant genotypes may be markers of a leukotriene dependent phenotype of asthma that responds well to treatment with a leukotriene receptor antagonist.

Differences in $\mathrm{LTC}_{4}$ synthase expression in eosinophils and other leucocytes may only be rate limiting for $\mathrm{LTC}_{4}$ synthesis when the 5-LO pathway is highly stimulated. Thus, in eosinophils from normal subjects, there was no difference in $\mathrm{LTC}_{4}$ synthesis in vitro between the variant and wild type genotypes in the absence of ionophore stimulation, and low levels of leucocyte activation in vivo may also explain the lack of difference in urinary $\mathrm{LTE}_{4}$ levels (fig 2B). However, stimulation of normal eosinophils with calcium ionophore revealed significantly increased $\mathrm{LTC}_{4}$ synthesis in subjects with the variant $\mathrm{LTC}_{4}$ synthase genotype (fig 2A). The difference became statistically significant in the presence of indomethacin, which prevents shunting of arachidonate along the cyclo-oxygenase (COX) pathway. This may explain why in most patients with AIA, who have a high prevalence of the variant LTC $_{4}$ synthase allele, ${ }^{16}$ exposure to aspirin and other COX inhibitors consistently provokes an acute surge of cys-LT synthesis leading to acute bronchoconstriction.

The increased prevalence of the variant $\mathrm{LTC}_{4}$ synthase genotype in the patients with severe asthma (56\%) compared with the normal subjects $(32 \%)$, and the concomitant increase in the capacity for $\mathrm{LTC}_{4}$ production in eosinophils when stimulated, suggests that a genetic propensity for enhanced cys-LT production in vivo may be a predisposing factor for severe asthma irrespective of aspirin sensitivity.

The study of two weeks treatment with oral zafirlukast in patients with severe chronic asthma was an open study involving a small number of patients $(n=23)$. Withdrawal of oral corticosteroids and other asthma medication before the study probably accounts for the deterioration in lung function observed in patients with the wild type LTC $_{4}$ synthase genotype. Against this background, patients with the variant genotypes showed a tendency to improvement in two measures of lung function $\left(\mathrm{FEV}_{1}\right.$ and $\mathrm{FVC}$; fig 3). Although not reaching statistical significance $(p=0.1)$, the results suggest that enhanced cys-LT synthesis contributes disproportionately to the pathophysiology of asthma in the $56 \%$ of patients with the variant $\mathrm{LTC}_{4}$ synthase genotype, and that these patients may represent the target group of good responders to anti-leukotriene therapy. Large scale clinical studies are planned to investigate this further.

APS is funded by a grant-in-aid from Merck \& Co and IS by a National Asthma Campaign project grant (99/049). STH is a Medical Research Council Clinical Professor (Programme grant no. G8604034) 
1 Sampson AP, Holgate ST. Leukotriene modifiers in the treatment of asthma: look promising across the board of treatment of asthma: look promising a

2 Diamant Z, Hiltermann JT, Van Rensen EL, et al. The effect of inhaled leukotriene $\mathrm{D}_{4}$ and methacholine on sputum cell differentials in asthma. Am $\mathcal{F}$ Respir Crit Care Med 1997; 155:1247-53.

3 Laitinen LA, Laitinen A, Haahtela T, et al. Leukotriene $\mathrm{E}_{4}$ and granulocytic infiltration into asthmatic airways. Lance 1993;341:989-90.

4 Leff AR, Busse WW, Pearlman D, et al. Montelukast, a leukotriene receptor antagonist, for the treatment of mild asthma and exercise-induced bronchoconstriction. $N$ Engl f Med 1998;339:147-52.

5 Cowburn A, Sladek K, Soja J, et al. Over-expression of leukotriene $\mathrm{C}_{4}$ synthase in bronchial biopsies of aspirinintolerant asthmatics. F Clin Invest 1998;101:834-46.

6 Seymour ML, Aberg D, Riise G, et al. Seasonal allergen exposure increases expression of leukotriene pathway enzymes and induces eosinophil influx in bronchial mucosa of atopic asthmatics. f Allergy Clin Immunol 1998;101:711 (abstract).

7 Lynch KR, O'Neill GP, Liu Q, et al. Characterization of the human cysteinyl leukotriene CysLT $_{1}$ receptor. Nature

8 Sarau HM, Ames RS, Chambers J, et al. Identification, molecular cloning, expression, and characterization of a cysteinyl leukotriene receptor. Mol Pharmacol 1999;56: 657-63.

9 Boyce JA, Lam, BK, Penrose JF, et al. Expression of LTC synthase during the development of eosinophils in vitro from cord blood progenitors. Blood 1996;88:4338-47.
10 Cowburn AS, Holgate ST, Sampson AP. IL-5 increases expression of 5-lipoxygenase-activating protein and transocates 5-lipoxygenase to the nucleus in human blood eosinophils. F Immunol 1999;163:456-65.

11 Sanak M, Sampson AP. Biosynthesis of cysteinylleucotrienes in aspirin-intolerant asthma. Clin Exp Allergy 1999;29:306-13.

12 In K, Asano K, Beler D, et al. Naturally-ocurring mutations in the human 5-lipoxygenase gene promoter that modify transcription factor binding and reporter gene transcription. F Clin Invest 1997;99:1130-7.

13 Silverman ES, Du J, De Sanctis GT, et al. Egr-1 and Sp1 interact functionally with the 5-lipoxygenase promoter and its naturally occurring mutants. Am F Respir Cell Mol Biol 1998;19:316-23.

14 Drazen JM, Yandava CN, Dube L, et al. Pharmacogenetic association between ALOX5 promoter genotype and the response to anti-asthma treatment. Nature Genet 1999;22: $168-70$

15 Szczeklik A, Stevenson DD. Aspirin-induced asthma: advances in pathogenesis and management. $\mathcal{F}$ Allergy Clin Immunol 1999;104:5-13.

16 Sanak M, Simon HU, Szczeklik A. Leukotriene C, synthase promoter polymorphism and risk of aspirin-induced asthma. Lancet 1997;350:1599-600

17 Bazan-Socha S, Sanak M, Szczeklik A. Expression of leukotriene $\mathrm{C}_{4}$ synthase (LTC4S) in peripheral blood leukocytes of patients with asthma. Eur F Clin Invest 1998;28: A50. 